\title{
Radiation Grafting of Polyethylene onto Conductive Carbon Black and Application as a Novel Gas Sensor
}

\author{
Jinhua Chen, Yasunari Maekawa, ${ }^{*}$ Masaru Yoshida, ${ }^{*}$ \\ and Norio TSUBOKAWA ${ }^{* *, \dagger}$ \\ Department of Material Science and Technology, Faculty of Engineering, Niigata \\ University, 8050 Ikarashi 2-nocho, Niigata 950-2181, Japan \\ ${ }^{*}$ Department of Material Development, Takasaki Radiation Chemistry Research \\ Establishment, Japan Atomic Energy Research Institute, 1223 \\ Watanuki-machi, Takasaki, Gunma 370-1292, Japan. \\ ${ }^{* *}$ Faculty of Engineering, Niigata University, 8050 Ikarashi \\ 2-nocho, Niigata 950-2181, Japan
}

(Received September 5, 2001; Accepted October 17, 2001)

\begin{abstract}
Radiation grafting of polyethylene (PE) onto carbon black was carried out by $\gamma$-ray irradiation of PEadsorbed carbon black. The percentage of PE grafting and decomposition temperature of PE grafted onto the surface were determined by thermogravimetric analysis. At low irradiation temperature, the percentage of grafting was very small in spite of higher irradiation dose. On the contrary, at high temperatures near or above the melting point of PE, the grafting of PE onto the carbon black surface proceeded and the percentage of grafting exceeded $90 \%$ when the irradiation dose reached to $200 \mathrm{kGy}$. The results indicate that the adsorbed PE was completely grafted onto the carbon black surface. The decomposition temperature of the grafted PE on the surface was higher than both free (unadsorbed) PE and adsorbed $\mathrm{PE}$ on the carbon black surface, indicating that there is a covalent bond between the carbon black and PE molecule. Using the PE-grafted carbon black and PE, conductive PE/PE-grafted carbon black composite was prepared. Electric resistance suddenly increased in cyclohexane vapor over $10^{4}$ times, and returned to initial resistance when transferred to air, indicating that the composite can be used as a novel gas sensor.

KEY WORDS Carbon Black / Radiation Grafting / $\gamma$-Ray / Polyethylene / Conductive Composite

/ Gas Sensor /
\end{abstract}

Carbon black is an important ultrafine inorganic material used industrially as reinforcing filler in tires, as a black pigment in plastic, ink and paint, and as an electroconductive material in conductive composites. The dispersibility of carbon black in organic solvents or polymer matrices is the most important parameter in the above carbon black-containing materials. Polymergrafted carbon black, a novel organic-inorganic hybrid, which suggests "a chestnut of bur", is known to remarkably improve the dispersibility of carbon black into polymer matrix. ${ }^{1-3}$

In general, the grafting of polymers onto the carbon black surface was successfully achieved by the radical, cationic, and anionic graft polymerization of various monomers initiated by initiating groups previously introduced onto the surface. ${ }^{1-3}$ The polymers were also grafted onto the carbon black surface by direct condensation of polymers with terminal functional groups with surface functional groups such as phenolic hydroxyl and carboxyl groups. ${ }^{1-3}$

We reported that crystalline polymer-grafted carbon black shows a large electric resistance response toward certain organic vapors, making them interesting materi-

${ }^{\dagger}$ To whom correspondence should be addressed. als for a novel gas sensor. ${ }^{4-8}$ In general, the conductive carbon black has no functional groups as grafting sites of a polymer. In previous studies, the grafting of PE onto conductive carbon black was achieved by the reaction of low molecular weight oxidized PE having hydroxyl groups with carboxyl groups on carbon black, which were previously introduced by the radical trapping method. ${ }^{8}$ However, the percentage of grafting was less than $2-5 \mathrm{wt} \%$.

Carbon blacks have ability to trap free radicals and act as a strong radical scavenger. ${ }^{9} 10$ We reported that the carbon black surface has ability to trap polymer radicals formed by the decomposition of azo-polymer and peroxide polymer to give the corresponding polymer grafted carbon black..$^{1-13}$

In the past five decades, nuclear radiation has made its entry into many chemical processes. It is said that 'polymerization', 'grafting', and 'curing', allimportant chemical processes in the polymer field, proceed through radiation techniques. ${ }^{14}$

$\gamma$-Radiation grafting is usually performed by preirradiating the matrix such as film, particles in the air to produce radicals, and then by reacting the irradiated matrix with a grafting monomer or polymer at a high 
temperature during a design time. ${ }^{15-19}$ However, few studies on the direct grafting of polymers onto inorganic particle surfaces in a dry state are undertaken. It is expected that PE radicals formed by $\gamma$-irradiation ${ }^{15}$ is successfully trapped by the carbon black surface to give PE-grafted carbon black.

This paper presents a simple method to irradiate PEadsorbed carbon black directly, which was effective to graft PE onto the carbon black surface. The percentage of grafting can be controlled by radiation dose and/or adsorbed amount of polymer when irradiation is performed at a high temperature near the melting point of the polymer. The response of electric resistance of the composite prepared from PE and PE-grafted carbon black thus obtained against cyclohexane vapor was investigated.

\section{EXPERIMENTAL}

\section{Materials}

Conductive carbon black, Asahi $60 \mathrm{H}$, was used to be grafted. It is a furnace black made by Asahi Carbon Co. Ltd. (Niigata, Japan). The specific surface area of the carbon black is $60 \mathrm{~m}^{2} \mathrm{~g}^{-1}$, and particle size is $41 \mathrm{~nm}$. The carbon black was dried in a vacuum at $110^{\circ} \mathrm{C}$ for $48 \mathrm{~h}$ before use. Polyethylene (PE), a linear low density type, was purchased from Aldrich Chemical Co., and used as received. It is copolymerized with $5-10 \mathrm{wt} \%$ hexene; the melt index is $100 \mathrm{~g} / 10 \mathrm{~min}\left(190^{\circ} \mathrm{C} / 2.16 \mathrm{~kg}\right.$, ASTM D 1238) and the density is $0.929 \mathrm{~g} \mathrm{~mL}^{-1}$. Analytical $m$-xylene, pursed from Wako Pure Chemical Ind. Ltd, Japan, was used without further purification.

\section{Adsorption of PE onto Carbon Black Surface}

$\mathrm{PE}$ was adsorbed onto carbon black surface as follows. $3.0 \mathrm{~g}$ of PE were dissolved in $100 \mathrm{~mL} m$-xylene at $120^{\circ} \mathrm{C} .2 .0 \mathrm{~g}$ of carbon black were added to the PE solution. The mixture was violently stirred at $120^{\circ} \mathrm{C}$ for $5 \mathrm{~h}$. After cooling, the suspension was allowed to stand at room temperature until carbon black completely precipitated. The supernatant solution was removed by decantation and PE-adsorbed carbon black was dried in a vacuum at $80^{\circ} \mathrm{C}$ for $24 \mathrm{~h}$. The amount of adsorbed PE on the surface was determined by TGA.

\section{$\gamma$-Ray Radiation Grafting of PE onto Carbon Black Surface}

The PE-adsorbed carbon black was sealed into a glass tube (Diameter $=7 \mathrm{~mm}$, Length $=50 \mathrm{~mm})$ with a rubber stopper. The air in the tube was completely replaced by nitrogen gas (nitrogen introduce at the bottom of the glass tube through a glass capillary for $5 \mathrm{~min}$ ). Irradiation was performed in Co-60 source fa- cility of JAERI (Japan Atomic Energy Research Institute) at a designed temperature (from $25^{\circ} \mathrm{C}$ to $140^{\circ} \mathrm{C}$ ). The samples in the tube were irradiated at $20-400 \mathrm{kGy}$ at dose rate of $20 \mathrm{kGy} \mathrm{h}^{-1}$. After irradiation, the product was immediately extracted with a Soxhlet apparatus for $48 \mathrm{~h}$ with $m$-xylene to remove the ungrafted PE. Ungrafted PE was almost completely removed by extraction with $m$-xylene.

\section{Percentage of Grafting}

The amount of grafted PE was estimated by TGA (thermogravimetric analysis, Shimadzu TGA-50, Japan). TGA analysis was carried out up to $600^{\circ} \mathrm{C}$, at a scan speed of $20^{\circ} \mathrm{C} \mathrm{min}^{-1}$ under a flow of nitrogen gas at $20 \mathrm{~mL} \mathrm{~min}^{-1}$. Sample weight was kept at 5$7 \mathrm{mg}$. The percentage of grafting was determined by the equation,

$$
\operatorname{Grafting}(\%)=(A / B) \times 100
$$

where $A$ and $B$ represent amounts of weight loss (decomposed PE) and weight residue (carbon black), respectively.

\section{Decomposition Temperature}

The decomposition temperature $\left(T_{\mathrm{d}}\right)$ of PE was defined as the peak of the first differential curve of TGA. Therefore, $T_{\mathrm{d}}$ means the temperature at which decomposition reaches the maximum rate $(-\mathrm{d} W / \mathrm{d} T)$.

\section{Sensor Material}

The sensor material was prepared from PE-grafted carbon black (grafting, 15\%) and PE. In the PE/carbon black conductive material, the carbon black content is $20 \mathrm{wt} \%$ (grafted PE not included in this part). The $\mathrm{PE} /$ carbon black composite was coated onto a ceramic plate equipped with $\mathrm{Pd} / \mathrm{Ag}$ electrode. The electric resistance of the electrode was recorded by an ohmmeter at $30^{\circ} \mathrm{C}$ every $10 \mathrm{sec}$ in dry air and then in saturated cyclohexane vapor. The details of the preparation for the sensor materials, measurements of electric resistance and response analysis are described in our previous papers. $^{4-8}$

\section{RESULTS AND DISCUSSION}

Irradiation Grafting of PE onto Carbon Black Surface

When pre-irradiated $P E$ was mixed with carbon black in $m$-xylene or decaline solution, the percentage of PE grafting onto carbon black was less than $2 \%$ even for a long reaction time at high temperature.

Therefore, the grafting of PE by irradiation of PEadsorbed carbon black was investigated. Figure 1 shows the relationship between the percentage of graft- 


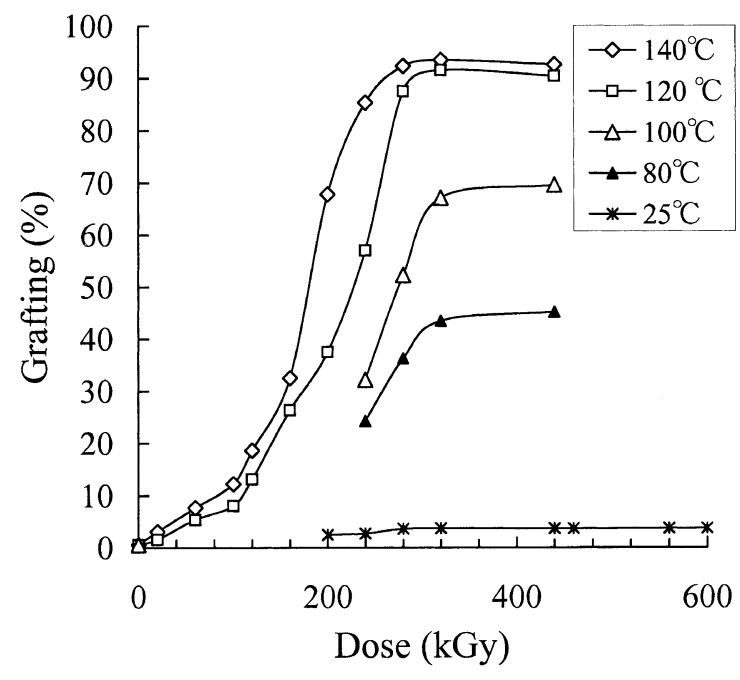

Figure 1. Relationship between percentage of PE grafting and irradiation dose at various irradiation temperatures. The amount of adsorbed PE on carbon black before irradiation is $94 \%$ (weight percent of PE to carbon black).

ing and irradiation dose at $25,80,100,120$, and $140^{\circ} \mathrm{C}$. The dose rate was fixed at $20 \mathrm{kGy} \mathrm{h}^{-1}$, so the total dose irradiated on PE-adsorbed carbon black was the product of exposure time and dose rate. The amount of PE adsorbed on carbon black was determined to be $94 \%, i$. e., 94 parts of PE were adsorbed on 100 parts of carbon black by weight.

As shown in Figure 1, the percentage of grafting increased with irradiated dose and reached a steady state (maximum grafting). It is interesting to note that the maximum grafting of $\mathrm{PE}$ onto the carbon black surface at each temperature is remarkably affected by irradiation temperature. About 260-300 kGy irradiation was needed to reach the maximum grafting at each temperature, in spite of irradiation temperature above $80^{\circ} \mathrm{C}$.

Figure 1 also shows an induction period in the irradiation grafting; PE grafting slowly increased in the initial $5 \mathrm{~h}(100 \mathrm{kGy})$, and then grafting rate increased for the next $10 \mathrm{~h}$ (at the range of $100-300 \mathrm{kGy}$ ). It is clear that the maximum grafting increased with irradiation temperature and reached about $90 \%$ at 120 and $140^{\circ} \mathrm{C}$.

This phenomenon indicates that after the induction period, with increasing irradiation dose, the reaction of PE radicals with the carbon black surface is accelerated because of acceleration of PE radical generation. At 120 and $140^{\circ} \mathrm{C}$, after $300 \mathrm{kGy}$ irradiation, the grafting reached a steady-state, the maximum grafting reached $94 \%$, because the adsorbed $\mathrm{PE}$ almost completely grafted onto the carbon black surface. Therefore, the grafting efficiency of PE (percentage of grafted PE to adsorbed PE) onto carbon black was $100 \%$.

The above results are explained as follows. In an adequate irradiation dose and high irradiation temperature near or above the melting point of PE, the movement of the PE molecule makes possible the reaction of the carbon black surface with generated PE radicals. So all of the adsorbed PE on carbon black was grafted onto the surface.

At $25^{\circ} \mathrm{C}$, even at $600 \mathrm{kGy}$, the percentage of PE grafting was less than $4 \%$ (maybe contain the crosslinked $\mathrm{PE}$ on carbon black), and grafting efficiency was only $4.3 \%$. This may be due to the fact that PE radicals cannot move enough to react with the carbon black surface because of the crystalline structure of PE.

Crosslinking of $\mathrm{PE}$ formed by irradiation cannot be removed by Soxhlet extraction with $m$-xylene and thus remained on the resulted carbon black surface. However, crosslinking of PE was confirmed to be less than $6.4 \%$ even under $600 \mathrm{kGy}$ radiation. As described below, in the presence of carbon black, the grafting of PE onto the carbon black surface is the main reaction under the above conditions.

In conclusion, the grafting of $\mathrm{PE}$ onto the carbon black surface successfully proceeded by irradiation of PE-adsorbed carbon black and the percentage of PE grafting onto the surface by radiation grafting was much larger than that by chemical grafting. ${ }^{4-8}$ Therefore, the radiation grafting onto carbon black is very effective to achieve the effective grafting onto carbon black having few functional groups, such as conductive carbon black.

\section{Mechanism of Grafting}

Radiation-based grafting processes have many advantages over other conventional methods. For the grafting of a polymer onto particle surfaces, the radiation grafting differs from chemical grafting. In the radiation yprocessing, no catalyst or additives are required to initiate the reaction. Especially, reaction media, such as a solvent, can be omitted. As no catalyst or additives are required, the purity of the resulting products can be maintained. Now, radiation grafting is a well established technique. ${ }^{15-19}$

$\gamma$-Irradiation of PE has been studied by many authors for the last 50 years. ${ }^{20-23}$ By irradiation of PE, at least three radicals of different lifetimes are produced and even the fast-decaying component has a long lifetime over 1 day in the atmosphere. ${ }^{24}$

As shown in Scheme 1(1)-(4), by $\gamma$-irradiation of PE, free radicals such as alkyl (1), allyl (3), and polyenyl radical (4) with different lifetimes, are generated in PE molecules. Polyethylene in this study contains methine carbon with butyl pendant. Therefore, it is considered that alkyl radical shown in Scheme 1 (2) also formed.

Even the lifetime of the fast-decaying alkyl radical 


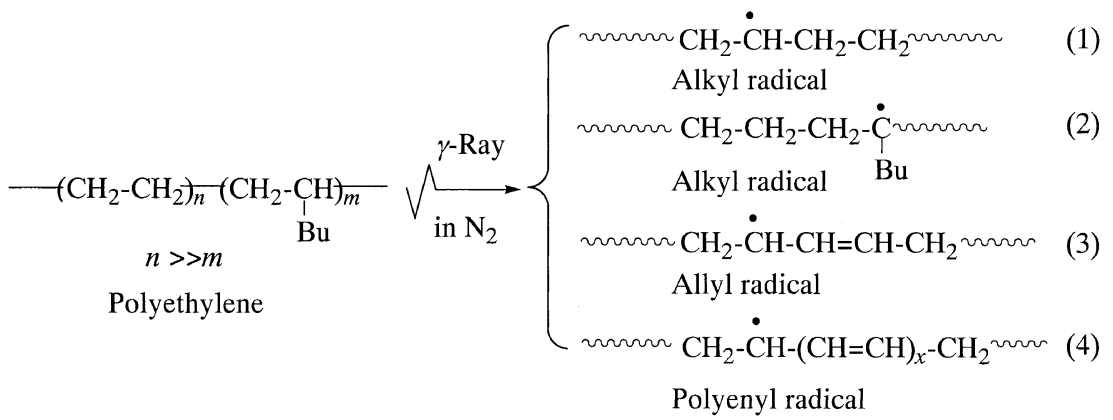

$$
\begin{aligned}
& \mathrm{C}_{\text {Carbon black }}+\text { Polyethylene radical }_{\text {Radical trapping }}^{\longrightarrow} \\
& \text { Polyethylene-grafted carbon black }
\end{aligned}
$$

Scheme 1.

is over several days. Therefore, it is considered that the crosslinking of PE through the coupling of these radials during the irradiation hardly proceeds. Abou Zeid et al. point out that the crosslinking of PE film by $\gamma$-irradiation at room temperature may be predominant only at high doses larger than $500 \mathrm{kGy} .^{25}$

In the presence of carbon black, PE radicals, especially alkyl radicals, formed by $\gamma$-irradiation are trapped by carbon black, because carbon black acts as a strong scavenger of polymer radicals to give PE-grafted carbon black as shown in Scheme 1 (5). The crosslinking between PE radicals in the presence of carbon black was obstructed. At higher temperatures and higher irradiation doses (correspondingly, the irradiation time was longer), however, it seems that the coupling of polymer radicals may happen, resulting in crosslinking between the grafted PE on the carbon black. Irradiated sample may remain in powder form at lower dose, bellow 300 kGy, whereas above $300 \mathrm{kGy}$ and with high temperatures, a silk-like carbon black aggregate was observed sometimes because of crosslinking of the grafted polymer on the carbon black surface.

\section{Thermal Property of Grafted PE on Carbon Black Sur- face}

The thermal stability of grafted PE on the carbon black surface was compared with adsorbed $\mathrm{PE}$ on the surface and free PE. As shown in Figure 2 a, untreated carbon black shows no weight loss by $525^{\circ} \mathrm{C}$. Free PE shows almost $100 \%$ weight loss when the temperature is raised to $550^{\circ} \mathrm{C}$. Therefore, from the weight loss of the PE-grafted carbon black, we can get the amount of PE grafted onto the carbon black surface.

From TGA curves, the grafted PE on carbon black has higher decomposition temperatures than those of both adsorbed PE and free PE. To estimate the ther-

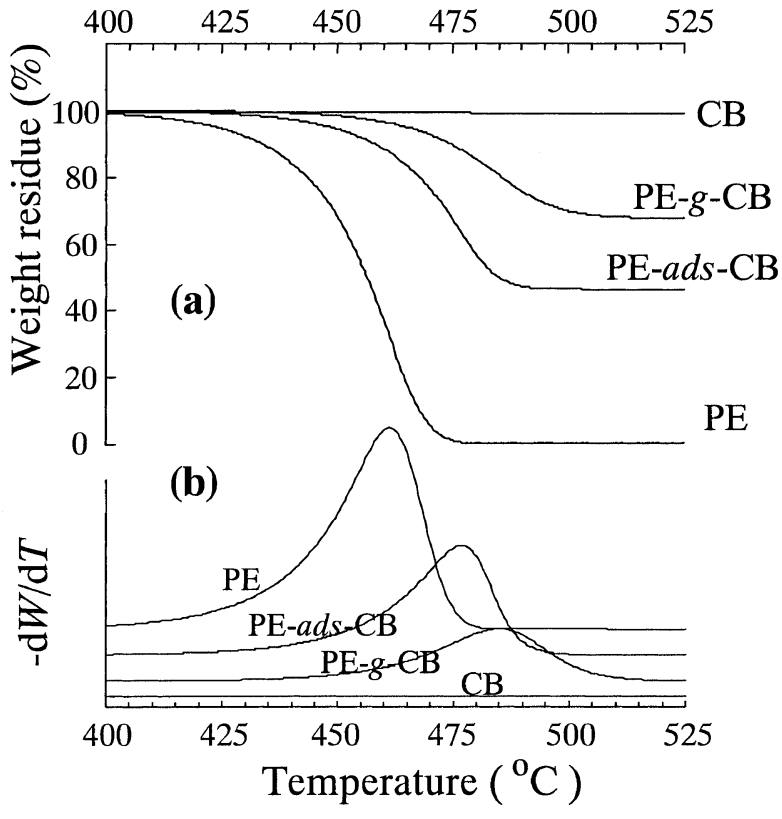

Figure 2. TGA curves of (A) carbon black, (B) PE-grafted carbon black (PE-g-CB), (C) PE-adsorbed carbon black (PE-ads-CB) and (D) free PE.

mal stability of grafted PE, adsorbed PE, and free PE, the decomposition rate $(-\mathrm{d} W / \mathrm{d} T)$ was calculated by differential TGA curve, and the results are shown in Figure $2 \mathrm{~b}$. The decomposition temperature $\left(T_{\mathrm{d}}\right)$ is defined as the temperature at peak of the differential TGA curves.

$T_{\mathrm{d}}$ of free PE, grafted PE on carbon black and adsorbed PE on carbon black decreased in the following order; grafted $\mathrm{PE}>$ adsorbed $\mathrm{PE}>$ free PE.

Figure 3 shows the relationship between $T_{\mathrm{d}}$ of PE of PE-grafted carbon black prepared from PE-adsorbed carbon black with a different dose irradiation at $120^{\circ} \mathrm{C}$ (sample the same as shown in Figure 1). The top and bottom dotted lines in Figure 3 refer to $T_{\mathrm{d}}$ of free PE and $\mathrm{PE}$ adsorbed on carbon black, respectively. $T_{\mathrm{d}}$ of 


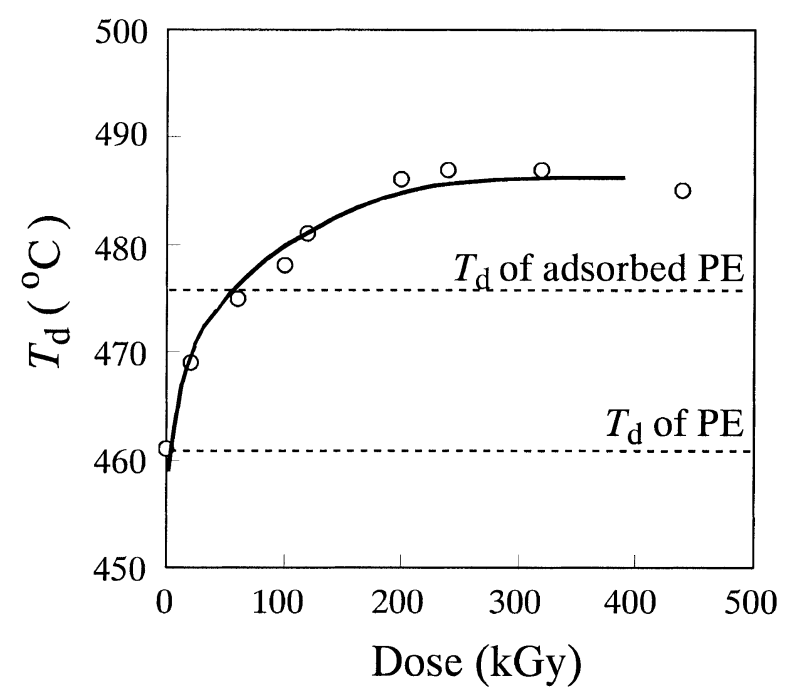

Figure 3. Effects of irradiation dose on decomposition temperature of grafted PE on the carbon black surface.

PE grafted on carbon black increased with irradiation dose up to $200 \mathrm{kGy}$. At $250-400 \mathrm{kGy}, T_{\mathrm{d}}$ was about $487^{\circ} \mathrm{C}$, and at $450 \mathrm{kGy}, T_{\mathrm{d}}$ slightly decreased.

Below $100 \mathrm{kGy}, T_{\mathrm{d}}$ of grafted PE is higher than that of free PE, but lower than that of adsorbed PE. It seems that this related to the induction-period as shown in Figure 1 , where the grafting is lower than $10 \%$.

\section{Application of PE-g-Carbon Black as Gas Sensor}

The composite prepared from a crystalline polymer and polymer-grafted conductive carbon black has a unique feature of electric resistance $(R)$ response when the composite is exposed to an organic solvent vapor. $^{4-8}$ This makes the composite become a new potential gas sensor material. In this study, an initial exploring investigation was conducted to find the effects of PE-grafted carbon black on the electric resistance response of the composite as a gas sensor material.

Figure 4 shows a typical response of electric resistance of the composite from PE-grafted carbon black and $P E$ against cyclohexane vapor. In one measurement cycle, resistance data of the composite were collected for $400 \mathrm{sec}$ in cyclohexane vapor; this was followed by a further $400 \mathrm{sec}$ data collection in dry air.

Electric resistance of the composite not only increases drastically in cyclohexane vapor, but also returns quickly to initial resistance when the composite is transferred to dry air. The response is very sensitive, as shown in Figure 4. When the composite was transferred from dry air to cyclohexane vapor, the electric resistance increased at a rate of about two orders of magnitude per minute, and when the composite was transferred to dry air, the electric resistance decreased at a faster rate of about three orders of magnitude per minute. The resistance change of the composite is re-

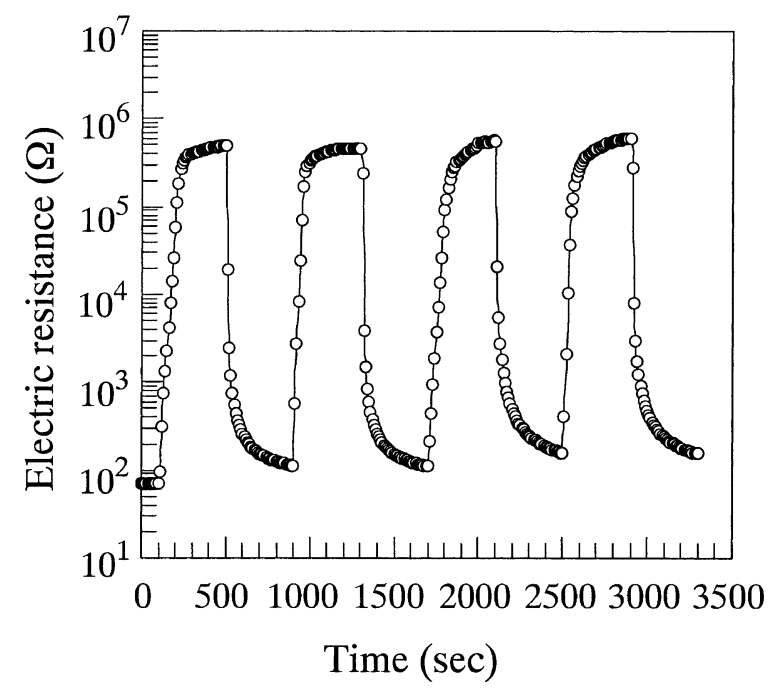

Figure 4. Electric resistance of the composite prepared from PE-grafted carbon black and PE in saturated cyclohexane vapor at $30^{\circ} \mathrm{C}$.

versible, and the response of electric resistance is excellently reproducible in every cycle of exposure to cyclohexane vapor and dry air, as shown in Figure 4.

The response of the electric resistance must be caused by composite structure change with absorption or desorption of the organic vapor. This can be applied to prepare a novel sensor to identify class solvents such as polar and non-polar solvents.

\section{CONCLUSIONS}

1. PE was successfully grafted onto conductive carbon black surface by $\gamma$-rays irradiation of PE-adsorbed carbon black. Maximum PE grafting onto carbon black by irradiation was much larger than that by normal chemical grafting.

2. At low irradiation temperature, grafting is very low even with higher irradiation doses, while at high temperatures near or above the melting point of $\mathrm{PE}$, grafting of PE onto carbon black reached about $90 \%$ at $200 \mathrm{kGy}$ or higher. PE grafting was readily controlled by the amount of adsorbed PE and/or adjusting the irradiation dose.

3. The decomposition temperature of grafted PE on carbon black is higher than free PE or adsorbed PE on the carbon black surface, indicating that a new interface between PE and carbon black is formed.

4. The electric resistance of the composite from PEgrafted carbon black showed reproducible and stable response to cyclohexane vapor by a signal of large electric resistance change. Therefore, the composite can be expected as material to prepare solvent or vapor sensor. 
Acknowledgment. This study was partly supported by a Grant in-Aid for Scientific Research from the Ministry of Education, Culture, Sports, Science and Technology of Japan. J. Chen is a Research Fellow of the Japan Society for the Promotion of Science.

\section{REFERENCES}

1. N. Tsubokawa, Prog. Polym. Sci., 17, 417 (1992).

2. N. Tsubokawa, Shikizai Kyokaishi, 71, 656 (1998).

3. N. Tsubokawa, "Fundamental and Applied Aspects of Chemically Modified Surfaces", J. P. Biltz and C. B. Little, Ed., The Royal Society, London, 1999, p 36.

4. M. Okazaki, K. Maruyama, M. Tsuchida, and N. Tsubokawa, Polym. J., 31, 672 (1999).

5. J. Chen and N. Tsubokawa, J. Appl. Polym. Sci., 77, 2437 (2000).

6. J. Chen and N. Tsubokawa, Polym. J., 9, 729 (2000).

7. J. Chen and N. Tsubokawa, Polym. Adv. Technol., 11, 101 (2000).

8. J. Chen and N. Tsubokawa, J. Macromol. Sci., Pure Appl. Chem., A38, 383 (2001).

9. M. Levy and M. Szwarz, J. Chem. Phys., 22, 1621 (1954).

10. M. Levy, S. Newman, and M. Szwarz, J. Am. Chem. Soc., 77, 4225 (1995).
11. N. Tsubokawa and K. Yanadori, Kobunshi Ronbunshu, 49, 865 (1992).

12. S. Hayashi, S. Handa, Y. Oshibe, T. Yamamoto, and N. Tsubokawa, Polym. J., 27, 623 (1995).

13. S. Yoshikawa, S. Machida, and N. Tsubokawa, J. Polym. Sci., Part A: Polym. Chem. Ed., 36, 3165 (1998).

14. A. Bhattacharya, Prog. Polym. Sci., 25, 371 (2000).

15. S. Ohnishi, S. Sugimoto, and I. Nitta, J. Polym. Sci., A, 1, 605 (1963).

16. J. Li, M. Zhai, M. Yi, H. Gao, and H. Ha, Radiat. Phys. Chem., 55, 173 (1999)

17. B. J. Ringrose and E. Kronfli, Radiat. Phys. Chem., 55, 451 (1999).

18. E. Akinay and T. Tincer, J. Appl. Polym. Sci., 79, 816 (2001).

19. G. Burillo, M. A. Oseguera, C. Vazquez, and L. F. D. Castillo, Radiat. Phys. Chem., 50, 511 (1997).

20. V. G. Barkhudaryan, Polymer, 41, 575 (2000).

21. V. G. Barkhudaryan, Polymer, 41, 2515 (2000).

22. J. Carlos, M. Suarez, and E. B. Mano, Polym. Degrad. Stab., 72, 217 (2001).

23. V. Premnath, A. Bellare, E. W. Merrill, M. Jasty, and W. H. Harris, Polymer, 40, 2215 (1999).

24. P. O'Neill, C. Birkinshaw, J. J. Leahy, and R. Barklie, Polym. Degrad. Stab., 63, 31 (1999).

25. H. M. Abou Zeid, Z. I. Ali, T. M. Abdel Maksoud, and R. M. Khafagy, J. Appl. Polym. Sci., 75, 179 (2000). 